\title{
Victims' Voices: The Impact of Online Grooming and Sexual Abuse
}

\author{
Helen C. Whittle ${ }^{1,2, *}$, Catherine Hamilton-Giachritsis ${ }^{1}$, Anthony R. Beech ${ }^{1}$ \\ ${ }^{1}$ School of Psychology, The University of Birmingham, Edgbaston, Birmingham, B15 2TT, UK \\ ${ }^{2}$ CEOP, 33, Vauxhall Bridge Road, Pimlico, London, SW1V 2WG UK \\ *Corresponding Author: helen.whittle@ceop.gsi.gov.uk
}

Copyright (C) 2013 Horizon Research Publishing All rights reserved.

\begin{abstract}
This paper reports one of the first studies to identify the impact on the victim of online grooming leading to online and/or offline sexual abuse. Eight young people (six females and two males) who had been victimised through online grooming and subsequently experienced sexual abuse online and/or offline were interviewed. Thematic Analysis was used to analyse the data. The impact of sexual abuse on the young person appears to be correlated with their level of vulnerability prior to the onset of grooming and also their experience with professionals following abuse. Most notably, those experiencing multiple long-term risk factors suffered greater negative impact after the grooming and abuse on an individual level (e.g., self-harm, depression), compared to those who had more protection. However, these individuals were also more likely to experience unsupportive and negative responses from their families. Therefore future research is required to further investigate this relationship. There is no evidence in this study to suggest that young people who are abused via the Internet suffer less harm than those who are abused offline. Based on the victim's direct experience of the services, recommendations are given for police, $\mathrm{ABE}$ (Achieving Best Evidence) interviewers, educationalists, and parents and carers.
\end{abstract}

Keywords Online Grooming, Victims, Child Sexual Abuse, Abuse Impact, Vulnerability

\section{Introduction}

The online grooming of children for the purpose of online and offline sexual abuse is a global problem that requires continued attention within research and practice [1-3]. Grooming (whether online or offline) can be defined as, " $A$ process by which a person prepares a child, significant adults and the environment for the abuse of this child." [4]There is increasing awareness of the need to evaluate this phenomenon and, whilst some work is beginning to consider the risk and protective factors for online grooming and abuse
[5], it is also important to consider the potential impact on young people of such abuse.

Child sexual abuse can be defined as, "forcing or enticing a child or young person to take part in sexual activities, not necessarily involving a high level of violence, whether or not the child is aware of what is happening" [6]. The impact of offline sexual abuse on a child or young person has been extensively studied and there are a range of potential consequences of child sexual abuse [7,8]. Among others, these include relationship difficulties $[9,10]$, post-traumatic stress disorder [11], mood disorders [12,13]and self-destructive-behaviour $[14,15,16]$.

It is important to note, however, that the impact of abuse on each victim is unique and many victims demonstrate considerable resilience when dealing with the impact of sexual abuse. Whether a victim experiences a particular problem or not is a result of complex interactions between a number of factors; these include how the individual victim makes sense of the abuse, the nature of the abuse, and the reactions and support given to the victim following abuse and other life experiences [7,17].Behaviours and coping strategies are often functional at the time of the maltreatment and only become dysfunctional when the immediate threat is removed (e.g. avoidant coping) [18]. In addition, many young people who have been abused experience multiple occurrences of victimization [19-22] and these young people are considerably more likely to experience psychological distress and trauma following abuse, than those who have experienced a single incident of abuse or no abuse at all [23,].

Sexual abuse which takes place online may include a child or young person being groomed and incited to engage in sexual activity; this can include sexual chat, generating sexual photos and/or generating sexual videos. They may also (but not necessarily) be encouraged to meet up offline. Victims of internet sexual abuse struggle with additional complexities (such as, having been in their own home, the possibility of the images being distributed online and the permanence of this) when dealing with the impact of abuse, and there is a need to challenge the presumption that victims of non-contact internet abuse suffer less harm than those who 
experience contact sexual abuse [24]. This includes online solicitation, which may or may not result in contact abuse.

Research has found that of young people who had experienced sexual solicitation online (although not necessarily from an adult), $28 \%$ felt very or extremely upset as a result and $20 \%$ felt very or extremely afraid afterwards[25]. When the online solicitation was aggressive, the negative impact increased to $34 \%$ and $28 \%$ respectively. Other negative effects of online solicitations included embarrassment, distress, being unable to stop thinking about it, stress, being jumpy or irritable, and losing interest in things [25]. Similarly, links have been found between young people who had experienced sexual solicitation online and experience of substance misuse and depressive symptomatology[26].

However, research that highlights the impact of online grooming and abuse, generally reports difficulties in establishing the direction of the correlation, i.e., whether these risk factors led the young person to be targeted online or whether these are consequences of the abuse[6,26]. Furthermore, it is imperative to consider how inextricably linked a young person's online and offline lives can be and the effect that one environment may have on the other, whether identifying vulnerabilities towards abuse or the impact afterwards [26,27]. For example, research comparing the impact of online and offline bullying found that personal variables associated with each individual are key in understanding the differences between the emotional impact on different victims [28]. It would be expected that similar variations are likely to be found with online sexual abuse.

Therefore, in light of the lack of knowledge regarding the impact on the young person of online grooming resulting in online and/or offline abuse, this research aims to qualitatively investigate young people's reports of the impact of online abuse, whether combined with offline abuse or not. Furthermore, victims' experiences of professional involvement following abuse are explored. By engaging directly with young victims, valuable insights can be gained regarding both the impact of the abuse and the experience of aftercare from police and social services.

\section{Method}

This study incorporated an explorative qualitative research design.

\subsection{Sample}

This research involved semi-structured interviews with six girls and two boys aged 13-18 years $(\mathrm{M}=15.88, \mathrm{SD}=2.17)$ who experienced online grooming between the ages of 12 and 14 years $(\mathrm{M}=12.88 ; \mathrm{SD}=0.84)$. In each instance the grooming led to sexual abuse either online and/or offline. All participants were white British and lived in a variety of locations across England. All of the offenders were male and grooming time ranged from 10 days to 18 months. Grooming time was defined as the first point of contact to the last point of contact with the offender.

The victims experienced a variety of abusive experiences. Specifically, three of the young people agreed to meet their abusers in real life and experienced contact sexual abuse. Of these, one participant left her home town with the abuser, another met the abuser twice during a year and the third participant had sex with her abuser several times a week for three months. Of the five young people who did not meet their abuser offline, abusive experiences again varied considerably. One victim's abuser was 17 years old and thus the case was interpreted as 'sexting' (peers sharing sexually explicit photos via technology), even though the victim was only 12 years old. This case and one other did not result in a conviction. Most victims (including two of those who met their offenders' offline) were incited to send a range of naked photos to the offender and some received similar photos in return. One victim was regularly incited to create images and videos during the course of a year, some of which were of an extreme sexual nature.

Notably, all of the females in this study considered their abuser to be a "boyfriend" at some point during the contact. In contrast, neither of the males considered the abuser to be a girlfriend. Both males in this study were groomed by the same offender; the boys knew their male abuser in the real world, but were unaware their online 'female' friend was this individual. The abuser targeted the boys specifically because of their offline friendship. Both males were under the impression they were talking to a female and sent 'her' several semi-naked photos of themselves.

\subsection{Procedure}

Police and Social Service professionals known to the Child Exploitation and Online Protection Centre (CEOP) were contacted about the research by the first author, either by email or by phone. Those that expressed an interest in the research or knew of a young person who might like to participate were sent further information with the following inclusion criteria: (1) the young person is currently aged between 12 and 18 years old; (2) the young person has been a victim of online grooming in the past; (3) the case relating to the grooming has now been closed; (4) the victim would like to participate in the research; (5) the professional associated with the case agreed that participation would have no detrimental effects for the young person; (6) the parent or guardian of the young person consents for the interview to take place. The exclusion criteria were as follows: (a) the young person is known to have mental health difficulties; and (b) the young person has severe learning difficulties. Once the professional had identified a young person who matched the criteria, they either approached the individual and their parent/carer or provided contact details for the first author to do so. The young person and their parent/carer were given an information sheet about the research.

\subsection{Ethics}


Ethical considerations were paramount to this research and the study was approved by the University of Birmingham Ethics Committee (Reference ERN 11-0083) and the CEOP Research Panel, ensuring all possible steps were taken to protect the participants. Professionals were asked to put forward only victims who they believed would have no detrimental effects from involvement. Participants were only interviewed on completion of consent forms from the professional associated with the case, their parent/ carer and the young person themselves. The young people were given as much information as possible about the research, prior to their involvement. This was provided via the information sheet, the consent form and explained in person immediately prior to interview. They were given the choice of having their parent/carer in attendance during the interview. All participants declined this. All data was anonymized in that personal details (including their name, names of others, place names and any other identifying features) were changed before analysis commenced. All references to the interview used the pseudonym and anonymized information. Therefore, the only information known about the individual, outside of the first author, was their age and gender. All pre-anonymized transcripts and voice recordings were destroyed.

All names and places in this paper are fictitious and the ages given with victim quotes (unless otherwise specified) are their age at the time of the grooming.

\subsection{The Interviews}

Interviews took place in a neutral setting (e.g., a victim suite at a police property) and lasted between 45 and 120 minutes. The first author conducted each interview, which was recorded using a Dictaphone. Before the interview commenced, information was given to the participant about their right to take breaks, refrain from answering questions, withdrawal from the research and the limits of confidentiality. Confidentiality could not be guaranteed if reference was made to a crime of which the police were unaware and it was made clear such offences would have to be reported. The interview commenced only after the consent forms had been discussed and any questions had been answered.

Each interview followed a chronological pattern and covered 11 topics: 1) Summary of what happened; 2) Initiation (including initial contact and feelings); 3) Manipulation (including perceptions of the offender and perceptions of self with offender); 4) Offender creating opportunity to abuse (including online and offline); 5) Preventing detection (including secrecy, reporting, police experience and reflections); 6) Internet use (including typical use and risk taking); 7) Family (including structure and family relationships); 8) Living environment (including feelings about living environment); 9) School (including feelings about school, internet at school and jobs); 10) Friends and romantic relationship (including friendship group and previous/subsequent relationships); 11) Self (including perception of self). Each topic generally began with a free narrative to encourage a participant-led interview. The interview plan was piloted with the first participant and then discussions were had between the interviewer and the second and third authors. One or two changes were made to the interview plan as a result of these discussions, however these were considered minimal, and thus the first participant was included in the main sample. Following the interview, participants were thanked and given a debriefing sheet with further information about the research, a reminder of the process of withdrawing (including the contact details of the interviewer) and details of a range of agencies that could provide additional support if required.

\subsection{Data Analysis}

The first author transcribed the Dictaphone recording immediately after the interview, which also assisted in familiarization with the data. Once transcribed, all personal information (i.e., names, place names) were anonymized and anonymous transcripts were imported into NVivo9 qualitative analysis software.

Qualitative analytic approaches vary considerably and they are either entrenched within a theoretical perspective, or independent of theory [29]. Thematic Analysis is often considered the foundation technique for qualitative work and is independent from specific theoretical perspectives [30]. Hence, Thematic Analysis seeks to identify, analyse and report themes within a set of data and has the flexibility to explore rich and detailed data without theoretical constraint [30]. For these reasons, Thematic Analysis was chosen as an appropriate methodology for this research. A bottom-up or data driven technique was utilized for this study, whereby no pre-existing theory was overlaid and consequentially themes were identified purely based on the content of the data.

The first author coded each interview by allocating the text nodes using NVivo9. Initial coding was considered complete when each line of the data had been assigned to at least one node. Following this, each interview was re-coded to capture any nodes created by subsequent interviews.

At this stage, sections of the text were analysed by the second author to provide inter-rater reliability. The codes identified by the second author were very similar to those produced by the first author. Where this was not the case, the authors explored the components of the code through discussion until agreement was reached. Following identification of approximately 800 nodes, the process then focused on establishing themes which linked the nodes. Nodes that were very similar or shared meaning were amalgamated into one node (for example, 'family money problems' and 'claimed benefits' were combined to become 'low income family') and nodes that were related to each other were combined to create themes using tree nodes (for example, 'given presents' and 'offered money' were joined under the tree of 'bribery'). Using data from all interviews, tree nodes gradually developed into connecting inter-related themes (e.g., offender manipulation techniques). Discussions 
between the first and second authors were frequent at this point in analysis and, once a comprehensive set of tree nodes were outlined, these were reviewed, defined and renamed until they accurately reflected the data. To clarify the journey in and out of abuse for each victim, individual life maps from birth until the end of the abuse were produced.

\section{Results}

During early analysis, three super-ordinate themes clearly emerged from the data:1) 'pre-offence', 2) 'during offence', and 3) 'post-offence' information. This paper focuses on data from the post-offence analysis, both in terms of impact but also on the experiences of post-abuse professional involvement.

Using the bottom-up method of analysis the participants described a range of consequences of the abuse, some negative and some more positive in nature, which broadly fell into categories of self, family, friends and school. Participants also identified a number of themes and lessons related to safe internet use.

Table 1. Themes relating to self (mentioned in twoor more interviews)

\begin{tabular}{|c|c|c|}
\hline Themes & $\mathrm{n}$ & Supporting Quotes \\
\hline $\begin{array}{l}\text { Psychological } \\
\text { impact }\end{array}$ & 4 & $\begin{array}{l}\text { "I don't think I'm gonna forget this } \\
\text { whole thing, yeah it'll get distant as I } \\
\text { grow older but I don't think I'll ever } \\
\text { forget it." Shelley, } 13 \text {. }\end{array}$ \\
\hline Embarrassed & 3 & $\begin{array}{c}\text { "I am embarrassed and humiliated } \\
\text { and it's horrible because now my } \\
\text { Mum and Dad know what happened." } \\
\text { Joanne, } 14 .\end{array}$ \\
\hline $\begin{array}{l}\text { Reminders of } \\
\text { Offender }\end{array}$ & 3 & $\begin{array}{c}\text { "When I'm alone in my room and I } \\
\text { hear this certain song, it does remind } \\
\text { me of him." Jenna, } 12 \text {. }\end{array}$ \\
\hline Self-Harm & 2 & $\begin{array}{c}\text { "I was self-harming as well... I landed } \\
\text { myself in hospital." Chloe, } 12 .\end{array}$ \\
\hline $\begin{array}{c}\text { Loss of } \\
\text { Confidence }\end{array}$ & 2 & $\begin{array}{c}\text { "I feel sometimes awkward around } \\
\text { people and I'm more self-conscious", } \\
\text { Charlotte, } 12\end{array}$ \\
\hline Aggression & 2 & $\begin{array}{c}\text { "I had aggression issues after all this } \\
\text { happened." Charlotte, } 12 .\end{array}$ \\
\hline
\end{tabular}

\subsection{Consequences Relating to Self}

Unsurprisingly, all discussions regarding outcome of the abuse on the individual were negative (Table 1). Half of the victims talked about a negative psychological impact and the fact that the abuse will resonate with them for a long time. In particular the victim associated with the 'sexting' case discussed feeling that she would never forget the abuse and it can ruin lives:

"Advice to anyone out there that wants to do it, don't. It ruins your life 'cause if you're like physically like kind of raped or hit or something, fair enough that's physical, but it's not as mentally, because you're thinking I let them do that to me" [Charlotte, 12]

Embarrassment was an issue for three of the victims, primarily relating to their parents knowing details of what had happened. However, most of the other themes were only mentioned by a quarter or fewer victims. For example, victims in two of the cases reported self-harm after the abuse: one of the victims described it as a way of coping with missing the offender. Feelings of aggression and lack of confidence were also mentioned by two victims, when discussing how they felt after the abuse was over. Additional themes articulated by one or two individuals included panic attacks, problems trusting others and feeling a sense of lost innocence.

Table 2. Themes relating to family - both negative consequences and more positive responses (mentioned in twoor more interviews)

\begin{tabular}{|c|c|c|}
\hline Theme & $\mathrm{n}$ & Supporting Quotes \\
\hline \multicolumn{3}{|l|}{ NEGATIVE } \\
\hline $\begin{array}{l}\text { Negative impact } \\
\text { on family } \\
\text { relations }\end{array}$ & 2 & $\begin{array}{l}\text { "Me and my dad we used to be } \\
\text { close. But since what happened, } \\
\text { it's like a little bit of distance cos it's } \\
\text { like to him, he let me get hurt." } \\
\text { Joanne, } 14 . \\
\text { "It was emotional distress as well } \\
\text { for the whole family...I just can't } \\
\text { really look at them in the same } \\
\text { way." Shelley, } 13 .\end{array}$ \\
\hline $\begin{array}{c}\text { Lack of parental } \\
\text { trust }\end{array}$ & 2 & $\begin{array}{c}\text { "I could tell that my parents didn't } \\
\text { trust me as much anymore." Mona, } \\
14 .\end{array}$ \\
\hline $\begin{array}{l}\text { Possible } \\
\text { violence to } \\
\text { offender }\end{array}$ & 2 & $\begin{array}{c}\text { "My uncle got a knife and was } \\
\text { gonna go to his door" Jenna, } 12 .\end{array}$ \\
\hline \multicolumn{3}{|l|}{ POSITIVE } \\
\hline Family support & 4 & $\begin{array}{l}\text { "They were still there for me, } \\
\text { through everything" Joanne, } 14 .\end{array}$ \\
\hline $\begin{array}{l}\text { Family more } \\
\text { protective }\end{array}$ & 3 & $\begin{array}{c}\text { "My Dad...he's got it so you can } \\
\text { track any of my messages sent from } \\
\text { my phone" Charlotte, } 13\end{array}$ \\
\hline
\end{tabular}

\subsection{Consequences Relating to Family}

In contrast to the self-themes, participants did report positive outcomes in relation to their family, as well as negative (Table 2). For example, at least half of the victims received the support they required from their family after the grooming/abuse was reported and described feeling cared for, particularly by their parents. An increase in the protectiveness of parents was emphasised by three of the victims, both online and offline. However, in some cases, this was interpreted by the victims as a lack of parental trust 
and a cause of frustration as they got older.

Negative impacts were reported by fewer participants. One quarter of participants reported a negative impact on family relations, most prominently two of the female victims discussed feeling distant from their fathers afterwards. This was largely related to feeling embarrassed and a sense that their father felt he had failed them.In contrast, one victim discussed feeling closer to her father after the abuse as they spend more time together now and talk more openly about her life.However, one victim aged 18 at the time of interview and no longer living at home recalled that her family reacted extremely badly and this, coupled with the lack of counselling support had extremely negative consequences for her.

"My Dad came and he hit me!Yeah, he blamed me for that completely, that was all my fault, that wasn't the paedophile that groomed me that was my fault that was, I was the little whore." [Chloe, 12 at offense, 18 at interview and now rarely in contact with her father]

Table 3. Themes relating to friends - both negative and more positive responses (mentioned in two or more interviews)

\begin{tabular}{|c|c|c|}
\hline Theme & $\mathrm{n}$ & Supporting Quotes \\
\hline \multicolumn{3}{|l|}{ NEGATIVE } \\
\hline Bullied & 2 & $\begin{array}{l}\text { "There was people that are spiteful } \\
\text { um, that don't understand what } \\
\text { you've been through." Joanne, } 14 \text {. }\end{array}$ \\
\hline $\begin{array}{l}\text { Difficult with } \\
\text { friends }\end{array}$ & 2 & $\begin{array}{c}\text { "A bit weird...they were a bit like, ah } \\
\text { what do I say?" Joanne, } 14 .\end{array}$ \\
\hline $\begin{array}{l}\text { Keeps it quite } \\
\text { private }\end{array}$ & 2 & $\begin{array}{c}\text { "It's not nice because it's not } \\
\text { something to talk about at all." } \\
\text { Jenna, } 12 .\end{array}$ \\
\hline \multicolumn{3}{|l|}{ POSITIVE } \\
\hline $\begin{array}{l}\text { Confided in } \\
\text { friends }\end{array}$ & 4 & $\begin{array}{l}\text { "She actually helped me so } \\
\text { much....Through things and things } \\
\text { like that." Jenna, } 12 .\end{array}$ \\
\hline $\begin{array}{l}\text { Romantic } \\
\text { support }\end{array}$ & 2 & $\begin{array}{c}\text { "He was really supportive and } \\
\text { understood and you know, I always } \\
\text { had, I always had him to talk } \\
\text { to...he's like the person that I } \\
\text { dreamed of back then, but he's } \\
\text { real." Joanne, } 14 .\end{array}$ \\
\hline
\end{tabular}

\subsection{Consequences Relating to Friends}

Half of the victims received support from their friends after the abuse and were able to confide in them. However, in the case of one victim, the mother of her close friend banned them from seeing each other, as she deemed the victim to be a bad influence. There were mixed opinions about relationships after the abuse; however, the length of time between the abuse and interview varied between six months and six years which is likely to impact the victims' thoughts and experiences regarding subsequent relationships. Most victims, who were spoken to several years after the abuse, went on to have happy and age appropriate short and long term relationships; one victim described falling in love a year after the abuse and is now married with children. However another victim described getting upset when a subsequent relationship (soon after the abuse) turned sexual and ended it. Despite this, at the time of interview (several years later) she was able to describe that this negative impact on relationships was temporary and she has now been able to move on. Two young people were interviewed a few months after the abuse and both had experienced several short term relationships with peers since. They did not report difficulties within these relationships; however one of these girls alluded to considerable impersonal sexual activity both before and after the abuse, although she did not report any negative emotions associated with this. In terms of friendships, two victims found these difficult after the abuse and did not wish to talk about it with their friends. In two cases the victims were bullied by peers who discovered information about the case. Both victims who experienced bullying demonstrated resilience by ignoring the bullies and continuing to move forward. These findings are summarised in Table 3.

\subsection{Consequences Relating to School}

There were was no discussions in any interview about schools responding negatively following the abuse (Table 4). Victims in $25 \%$ of cases described being given one-to-one or small group support during school hours. In the case of Chloe (who received little support from her family following the abuse), it was eventually the school who detected her depression and suicidal feelings, and as a result provided counselling and additional support. At the time of interview she was 18 years old and felt she had managed to move beyond that point in her life, including beginning a new relationship.

Table 4. Themes relating to school (mentioned in two or more interviews)

\begin{tabular}{|c|c|c|}
\hline Themes & $\mathrm{n}$ & Supporting Quotes \\
\hline Teacher's & 2 & $\begin{array}{c}\text { "You chat to them about things. It's } \\
\text { dead confidential whatever stays in the } \\
\text { room. What you talk about's got to } \\
\text { stay in that room." Jenna, 12. }\end{array}$ \\
\hline
\end{tabular}

\subsection{Consequences Relating to Internet Use}

The overwhelming trend when comparing the victim's Internet use before and after the abuse is that all victims were generally demonstrating safer online behaviours afterwards (Table 5). 'Telling someone if they were worried online' and 'using the internet less intensely' were reported by five participants. Other safer behaviours included 'protecting personal information online' and 'only speaking to those they know in the real world'

One negative outcome was one 12 year old victim who described being temporarily 'addicted' to sexting immediately after the abuse; despite the fact her father replaced her smartphone with an older model without Internet connectivity. This was particularly apparent a few 
months later when she started a new relationship with a peer.

"Even after all this; it became part of who I was. It was imprinted in my mind, photo, photo, photo, whenever I wanted to impress him; the first word I thought of was photo. It became an addiction almost, I had to find other, at one point I even started, because I couldn't take a photo, I would stand in front of the mirror pretending that I was taking a photo. It became a, it's really weird but it became an addiction, like it felt like it became the addiction of someone saying I'm sexy and good looking. I liked it." [Charlotte, 12 at offence, 13 at interview]

Table 5. Themes related to Internet use (mentioned in two or more interviews)

\begin{tabular}{|c|c|c|}
\hline Themes & $\mathrm{n}$ & Supporting Quotes \\
\hline $\begin{array}{c}\text { Would tell } \\
\text { someone if } \\
\text { worried now }\end{array}$ & 5 & $\begin{array}{c}\text { "I'd report them straight away to } \\
\text { whatever website, I'd block them, I'd } \\
\text { make sure they could not contact me in } \\
\text { anyway." Mona, } 14 \text {. }\end{array}$ \\
\hline $\begin{array}{c}\text { Less Internet } \\
\text { use }\end{array}$ & 5 & $\begin{array}{c}\text { "All I go on now is Facebook and also } \\
\text { I like just browsing the web for clothes } \\
\text { and parts for a motorbike and stuff like } \\
\text { that. I don't really go on it a lot } \\
\text { compared to what I used to do." } \\
\text { Jonathan, } 13 \text {. }\end{array}$ \\
\hline $\begin{array}{c}\text { Doesn't share } \\
\text { personal } \\
\text { information }\end{array}$ & 3 & $\begin{array}{c}\text { "But now I've learned like I can hide } \\
\text { stuff like my photos, erm my } \\
\text { information and stuff like that." } \\
\text { Joanne, } 14 .\end{array}$ \\
\hline $\begin{array}{l}\text { Doesn't } \\
\text { speak to } \\
\text { strangers } \\
\text { online }\end{array}$ & 3 & $\begin{array}{c}\text { "Now I'm more, I try and be more safe, } \\
\text { like I said know who I'm speaking to } \\
\text { when I'm speaking to someone.” } \\
\text { Lucas, } 13 \text {. }\end{array}$ \\
\hline
\end{tabular}

\subsection{Patterns of Abusive Impact}

To clarify trends across all participants, the distal consequences of abuse for each victim were outlined and then compared. These again fell into the domains of self, family, and friends/school, but positive changes in Internet use were also apparent. An example of this for one victim is highlighted in Table 6.

Notably, within this sample, whether abuse occurred online-only or both on- and offline did not correlate with the extent of the impact on the victim. Instead, links began to emerge between the young person's life before the grooming began and the impact of the abuse on the individual. For example, in an earlier analysis, victim vulnerabilities to online grooming were found to fall into three groups (Whittle, Hamilton-Giachritsis, \& Beech, in Submission): those with multiple long-term risk factors, those with trigger events and those with no risk factors but who took online behavioural risks. Similarly, differences in outcome seemed to fall across these same three groups:
1. Multiple long-term risk: those individuals who had long-term risk factors for on and offline abuse prior to the grooming showed a significant negative impact of abuse, particularly relating to the individual (e.g. self-harm, depression).

2. Trigger events: the group of participants who had lost protective factors prior to the grooming due to some trigger event (e.g., serious family illness, divorce, death) and who then became vulnerable, tended to show some negative impact from the abuse, but previous protective factors began to be reinstated and appeared to help their recovery.

3. Online behavioural risks: this 'category' related to one male victim who had no apparent risk factors prior to the abuse and who showed comparatively less negative impact than the other groups, potentially due to the protective environment surrounding the young person.

Table 6. Consequences of abuse for one individual victim

\begin{tabular}{|c|c|}
\hline \multicolumn{2}{|c|}{ Distal Consequences } \\
\hline Positive & Negative \\
\hline \multirow[t]{2}{*}{ Individual } & \\
\hline & Individual \\
\hline Family & Shame \\
\hline \multirow[t]{3}{*}{ Support from parents } & Embarrassment \\
\hline & Unable to forget abuse \\
\hline & Family \\
\hline & Family threatening violence \\
\hline Friends/School & towards offender \\
\hline Supportive friends & Difficult relationship with \\
\hline Supportive boyfriend & dad \\
\hline Internet Use & Friends/School \\
\hline $\begin{array}{l}\text { Protecting personal } \\
\text { information online }\end{array}$ & $\begin{array}{l}\text { Difficulty with sexual } \\
\text { relationship with boyfriend }\end{array}$ \\
\hline Less intensive use of internet & \\
\hline $\begin{array}{l}\text { Stopped speaking to } \\
\text { strangers online }\end{array}$ & Internet Use \\
\hline $\begin{array}{c}\text { Would tell someone if } \\
\text { worried about something } \\
\text { online }\end{array}$ & \\
\hline
\end{tabular}

This is shown diagrammatically in Figure 1below. For example, those who were temporarily vulnerable due to trigger events usually found their protective factors were reinstated. However, those with multiple long-term risk factors appeared to have more negative consequences of abuse; most likely due to the extent of pre-existing risk factors and limited protective factors, but also due to poor post-abuse reactions. However, caution must be taken with respect to the last category, in particular, given that only one participant showed this pattern, but it is worth considering in future research. 


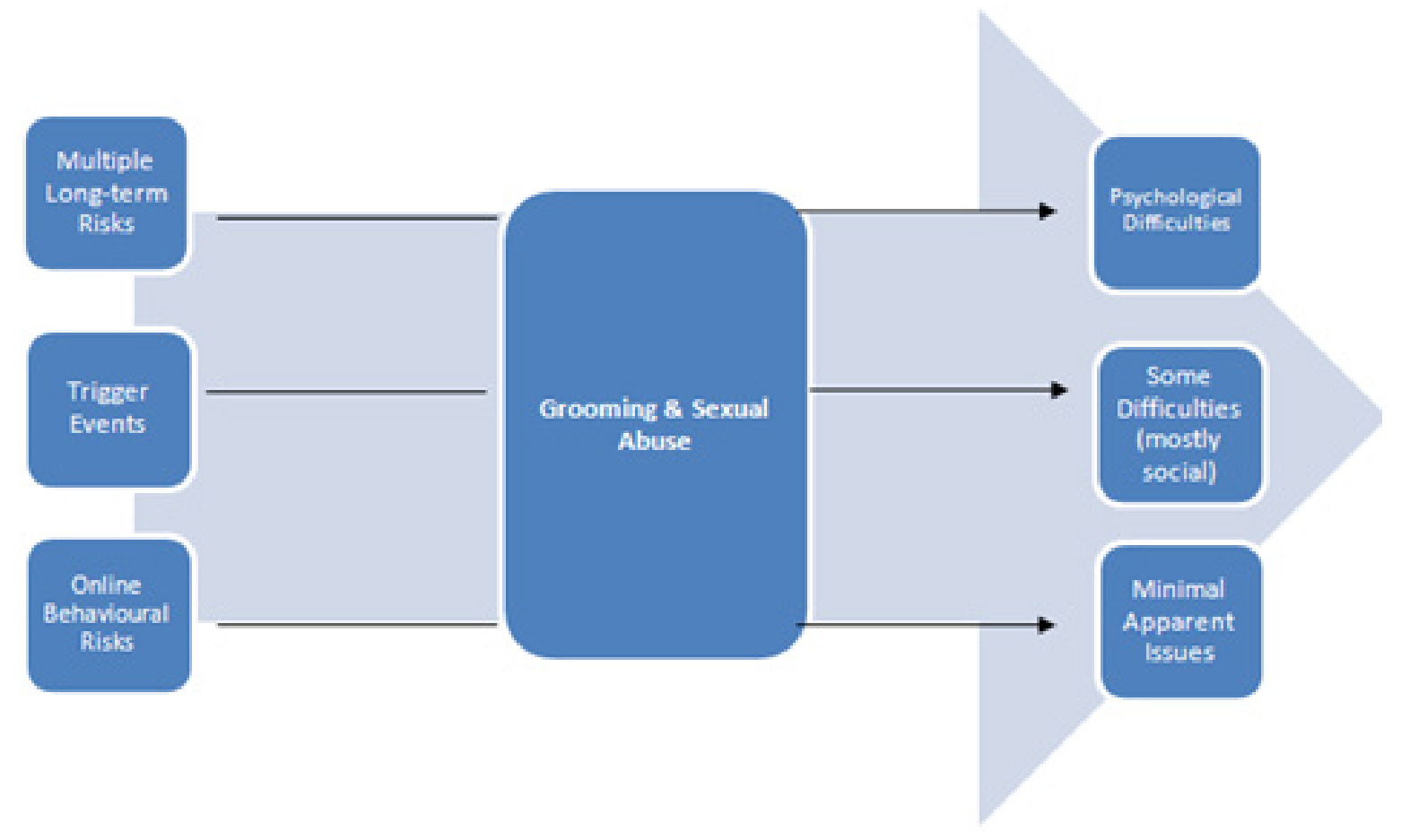

Figure 1. Routes in and out of abuse

\subsection{Post-Abuse Professional Involvement}

\subsubsection{Reporting}

No victim in this study voluntarily disclosed abuse. Half of the cases involved the parents finding out about the offender (either from a friend or by finding evidence of the relationship) and reporting directly to the police. In the other four cases, the police identified victims from offenders' computers as part of a wider investigation. Four victims were still in contact with the offender at the time of police intervention (50\%), and two of the victims (25\%) were found with their offenders during arrest.

"I lost my phone and I'd left all my conversations on my phone. Family (brother)found it, went through my phone, found everything, told my Mum and Mum told the police. [Charlotte, 12]

"When they [police] searched his computer they found everything Like his conversations with me, all the pictures, like videos and stuff. And then they found it off other people, they found out all this stuff which he'd had there." [Mona, 14]

My Dad rang the police looking for me and then he went over to my mates to meet Claire, and erm Claire, Claire told him everything." [Jenna, 12]

One victim (who had been regularly meeting her offender) assisted him during the arrest by hiding in a house with him and turning off her phone so they could not be tracked. The offender also told her to say 'no comment' when she was interviewed by the police. In contrast to half the victims who were extremely shocked by the truth about their offender's identity, this victim was angry with the police for ending her relationship with the offender.

"He went just turn your phone on and I went 'why?' So I turned my phone on because apparently he could have got done more for keeping me hostage or something like that.I was like I know they're gonna get, gonna get you and everything, like to Pete. I was like, I know they're gonna get you and I was worried." [Jenna, 12]

None of the victims gave evidence in court, but some had parts of their ABE (Achieving Best Evidence) interview video played in court. Half of the victims mentioned that the offender did not get a long enough sentence. Notably, of the four young people who thought this, three had described feelings of love towards the offender, but were appalled when they either found out the offender's true identity or were informed that he had multiple victims.

\subsubsection{Counselling}

Seven of the eight victims were offered counselling and most of those who were offered it accepted the support. Those who attended counselling reported that it was helpful to talk to a professional outside of the family and found it a positive experience.

"I went to victim support erm, for a little bit, she just like made me, like got me to jot things down in a book and like chat through, like for an hour a week. And that made me feel good, being able to talk to someone outside of my family, because like when you get home to your family they're like all questions fired at you and plus all the hugging and the crying. So it's like you need someone different as well to speak to you, to actually understand and someone that you 
can just write it down on a piece of paper, they read it, have a little chat and then it's gone, out the way." [Joanne, 14]

"It was quite helpful because there were still some things that were going on in my head that didn't make sense to me until I started talking about it here." [Mona, 14]

The final victim wanted counselling but described being put 'to the bottom of the pile' and initial discussions regarding additional support did not materialise into any sessions. This was particularly unhelpful for this victim as she lacked support in other areas of her life and had been blamed by her father.

"I was supposed to have a social worker come and see me, like a few weeks after it had happened and oh no they were too busy, something more important came up so I ended up at the bottom of the social work list again. So I ended up like not getting, not going through it with anyone, not counselling, not getting counselling or anything for it. So I just sort of buried it all, not thinking about it, it didn't happen, they didn't have time for me apparently" [Chloe, 12]

"If it had happened again, I would want counselling.I would want it from the start. Like I think that was the main thing that made it all so much worse for me, was because I didn't have anyone to talk to when it, just after it had happened." [Chloe, 12]

\subsubsection{Experience with the Police}

The victims from all victim vulnerability scenarios gave many positive comments about police involvement and generally held the officers who dealt with them in high regard. Feedback included that the police were effective, supportive, consistent and easy to talk to.

$\mathrm{ABE}$ interviewing is routinely used by police forces across the UK and victims of child sexual abuse are likely to experience this form of interviewing as part of the investigation. Key concepts covered within $\mathrm{ABE}$ interview guidance include: planning and preparation, rapport building, question formation, closing the interview and evaluation [31].In support of this, the importance of establishing and maintaining rapport was emphasised by the victims' comments in this study

"They made ya laugh and smile, even though ya know, after everything that you've just gone through, it's like that little laugh and that little bit of smile they put on your face is like, for them to say like everything's gonna get sorted out, everything's gonna ya know take it's time but it's gonna be alright. It's just a big like relief.They were brilliant, they were, couldn't ask for anybody better to have come and picked me up and to be there with me by my side." [Joanne, 14]

Victims also identified that it is beneficial to have a consistent police officer from the onset of the case, who they can contact throughout. Several victims were still in contact with their police officer and had their contact details should they ever need them. Most victims found this reassuring.

"Like I've kept in good touch with him, I could email, if I needed anything I could email him,ring him on his extension number whatever if I needed it quicker than email. Um, but he's been absolutely brilliant." [Shelley, 13]

A face to face meeting in the victim's home was the preference for initial contact, particularly when the victim was being informed about the investigation for the first time (e.g., when they were unaware the offender was an adult or was speaking to other young people). However, the $A B E$ suites used by the victims in this study were considered to be fairly comfortable and appropriate for the interview stage. In particular, victims appreciated suites that 'felt like a sitting room'; with comfortable seats, large windows and soft furnishings.

With regard to the actual $\mathrm{ABE}$ interview, most felt in control of the situation, and experienced no pressure from the officers.

"I was tired I was niggly I was shaking and they were just completely calm with me, didn't make me worried." [Charlotte, 12]

"Didn't really pressure me into saying anything that I didn't, they made it comfortable for me to talk to them." [Jonathan, 13]

In contrast, one victim felt the questioning was too persistent and that the officers spoke too quickly; she felt more time was needed to process the question and consider her answer.

"How persistent they were if I couldn't think of how to word something, they'd still ask me the same question until I could think about how to find the word. They'd ask me like threelfour times.I was like you've got really thick accents, I can't understand you when you're speaking so fast, go a bit slower!" [Mona, 14]

Alongside these generally positive comments, half of victims (across all victim vulnerability scenarios) had minor negative comments regarding their involvement with the police. Some of these comments related to aspects of the investigation that is necessary procedure, such as the case taking a long time to get resolved and different opinions regarding the level of parental involvement. Furthermore, half of the victims in this study found the ABE interview very difficult, nerve racking and, at times, embarrassing and long, but they generally understood the importance of their involvement in an interview.

In terms of gender of interviewers, at least one female victim was interviewed by two males and, whilst two victims had no preference, most victims specified a preference for a least one officer of the same gender.

"At first I was a bit uncomfortable it was a bit nerve racking at the beginning because it was two men." [Shelley, 13]

However, two participants(both from the multiple long term risk factors vulnerability scenario) had more serious negative concerns. In particular, Jenna (who was hiding with the offender on the night of the arrest), was upset that police broke up the relationship and then heard an officer make a judgemental comment about her outfit. As a result she felt looked down on by the officers and not listened to; this combination of events resulted in a loss of rapport between 
the officer and the victim.

"They just talk to you dead nasty like you've done something wrong. I'll talk to anyone about it, but if they're gonna like talk to me dead snotty, the way the police did, I won't talk to them.If they're not going to listen to you, you're not gonna tell them the answers to the questions." [Jenna, 13]

A need to resolve the investigation as quickly as possible was noted by the victims, as this generally assisted them with closure and enabled them to move forward. Yet, one victim was not informed about the outcome of the case and this caused her difficulties in recovery.

"My Nan she lives practically near him and I hate going to her house and walking down to the bus stop. Because I don't know if he got sent down or if he just got reprimanded and he's still round his house, house area. You know, I could see him walking down the road and I could be scared, I was scared." [Charlotte, 12]

Despite positive and negative comments regarding police and counselling services being generated by victims across all victim vulnerability scenarios, less positive experiences appear to cluster around the victims who were vulnerable due to multiple long term risks. For example, although happy with the police involvement, Chloe received no support from social services and experienced negative impact following the abuse. In the case of Jenna, despite being happy with the support group at school, she was unhappy with elements of her relationship with the police. The third individual within this vulnerability scenario is Charlotte, who spoke positively about the support given by the police, but the lack of information provided by them regarding the case outcome caused her problems with moving on. Within the other two victim vulnerability scenarios, negative comments regarding police and social services involvement were comparatively minor and as mentioned above, there was less psychological impact of the abuse for these victims.

\section{Discussion and Implications}

\subsection{Links between Victim Vulnerability Scenarios and Abuse Impact}

There is no evidence in this study to suggest that those who were also abused offline experienced greater negative impact of abuse than those who were abused online only. This supports emerging research [24]. Instead, the negative effects of abuse appear to be correlated with the risk and protective factors impacting upon the individual before the onset of the grooming. This is consistent with previous research reporting that young people are subject to influences from different areas within their lives [32], and these areas are equally applicable to abuse online and offline [6]. Moreover, the finding that negative offline events affecting the victims (e.g., bereavement, social isolation, family difficulties) influenced the impact of the online abuse (e.g., embarrassment, self-harm, family support), supports existing research regarding inextricable links between online and offline environments [26,27].

Many of the negative consequences of abuse on an individual level reported by victims in this study were consistent with previous research surrounding the impact of sexual abuse on victims, including psychological difficulties, shame, embarrassment and aggression [25]. Unsurprisingly, support from family, friends and school following the abuse assisted the victims in recovery, whilst negative reactions from the family, in particular, generated greater challenges for the victims during recovery. For example, those victims who had become more vulnerable following a trigger event that led to the loss of protective factors (e.g.,serious parental illness; divorce) generally found their protective factors were reinstated after the abuse. This assisted the victims in forming resilient reactions and improved coping.

In contrast, victims who had experienced multiple long-term risk factors most commonly reported the abuse as having considerable negative effects on them. The two victims who self-harmed following the abuse, were both within this vulnerability scenario. However, for one of these victims, self-harm was largely related to missing the offender and therefore it is important that professionals working with victims do not make assumptions about their feelings and abuse impact. It is also important to consider the cumulative nature of these experiences. For example, one girl, had been abused offline prior to the online grooming and abuse and thus, she had the compounding impact of experiencing subsequent revictimization[23,33]. This young person was in the multiple long term risk factor vulnerability scenario and appeared to experience more negative psychological impact of the abuse, when compared to those in the remaining two victim vulnerability scenarios.

This study therefore provides evidence to suggest that the risk and protective factors impacting a young person prior to abuse are linked with the potential consequences after the abuse. It also shows it is important to recognise that victims of abuse who experience multiple long-term risk factors in their day to day lives and who are unsupported within their family environment are likely to need extensive support from police and social services to minimise the abuse impact.

\subsection{Police Involvement}

Not only does this study highlight the relevance of a young person's life experiences affecting the impact of abuse, but the way the victim is dealt with by professionals can directly contribute to the minimisation or maximisation of abusive impact.

Following reported sexual abuse, victims frequently engage with police and social services to both gain support and to provide evidence for investigation. Victims of sexual abuse regularly engage with police and social services and give evidence within the $\mathrm{ABE}$ format, thus lessons can be learned from those who have experienced the process. All the victims in this study experienced an $\mathrm{ABE}$ interview and their feedback about this procedure can provide useful 
insights for practitioners.

Officers should not underestimate the importance of rapport to the victim and the impact this relationship has on the information given in interview and, hence, on likely conviction of the offender. The victims acknowledged that it was a difficult time in their life, thus an approachable and supportive officer who understands the complex nature of this type of crime was appreciated. For example, understanding that the victim may still care for the offender is crucial and an attitude contrary to this is likely to damage rapport with the young person. Furthermore, comments made in the presence of, or toward the victim should be sensitive and non-judgemental. Inappropriate comments by officers risk further harm to the victim and jeopardise rapport, thus are likely to reduce the quality and volume of information given in interview. Indeed, there is a need to ensure that training adequately addresses myths about victims to ensure that police officers do not succumb to stereotypes, such as those regarding dress.

More generally, during an officer's first contact with a victim, a comprehensive description of what the process involves will help clarify the procedure for the young person and manage expectations regarding the length of time until trial. Additionally, the victims also reported a desire to be kept informed about the progress and outcome of the case, as they may feel anxious about what they do not know.

To aid comprehension of the question and allow considered answers, the victims highlighted the need for the interviewers to go slowly and leave pauses in the conversation. Furthermore, having regular breaks in the interview was reported by the victims as positive, as it not only provided thinking time, but gave them respite from questioning on such a sensitive issue. Feeling in control of the interview (for example, being able to request a break or drink when needed) was also reported to be helpful. This should be emphasised by the officer during the interview introduction, to ensure the victim is aware of this option in the interview.

Based on the victims' feedback, interviewer selection is fundamental in meeting the needs of the victim and helping to provide an environment where the victim is able to talk openly about the offenses. While the majority of the victims preferred to have at least one interviewer of the same gender, two victims did not mind about this. Therefore, where possible, forces should consult the victim about gender preferences of interviewing officers and consider implications from details of the case (e.g., gender of offender). Furthermore, given the findings relating to police consistency and rapport, consideration should be given to appoint interviewers (particularly lead interviewers) based on those the victim has already engaged with or those who have established good rapport.

\subsubsection{Key Messages for Police}

-Establishing rapport (including being supportive and approachable) with victims is pivotal in generating good evidence and assisting victim recovery.
-Understand the complexity of the grooming process and the fact that the victim may still love their offender.

- Comments made to or in front of the victim should be sensitive and non-judgmental.

- Training of officers needs to include challenges to popular myths and stereotypes about victims

- Clarify the investigative process and timeframes at first contact with the victim to manage expectations.

-Keep the victim informed as the case progresses.

-Where possible, consider the victims preferences when assigning an interviewer, taking into account the gender of the offender and which officers already have a good rapport with the victim.

-In interview, go slowly and include breaks

- Limit the number of officers interacting with the victim to enhance consistency and rapport.

\subsection{Counselling}

Victims provided with victim support, counselling or advisory sessions through social services or school found this process aided their recovery and helped to minimise the negative impact of abuse. The provision of support from an impartial professional should be a basic entitlement for victims of online grooming and several victims noted that the objectivity and perspective of the professional was invaluable. In the case of Chloe, where the offer of counselling did not come to fruition, the negative impact of abuse was significant. This is also linked to the multiple risk factors in her life at the time and negative responses of her parents to the abuse. However, had counselling(for her and for her family) been implemented immediately after the abuse, she is more likely to have received the support that she desperately needed, which may have helped to limit the negative impact of the abuse.

\subsection{Online Safety Education}

All victims reported behavioural changes and appear to be considerably safer online now (see Table 5). This may have been a direct result of the abusive experience and inter-related factors, such as increased parental discussion of online safety. It may also have been supported by the fact that most have now received Internet safety education through their school. The majority of the victims acknowledged that now they are older, they have had Internet safety lessons in school and reported these to be helpful and necessary at a younger age. Many victims talked about the necessity for engaging, persistent and interesting internet safety lessons from an early age. Several thought that incorporating the experiences of young victims within this education would help get the messages through to young people. Victim recommendations for other young people included don't speak to people you don't know online, meet up with them or share personal information online

The role of parents and carers in protecting their children online was also mentioned by the victims, in particular, the 
importance of involving parents in Internet use, monitoring online activity and keeping access to the Internet in a family room. However, parental monitoring needs to be implemented in a way that the young person accepts. Open discussions between family members regarding why monitoring is necessary, how it will be implemented and the impact on the young person can aid this process. Ensuring the young person is involved in the decision making process about what is monitored will aid their compliance and lessen the impression of being patronised.

The majority of victims said that young people should stay aware when online and tell an adult if they are concerned. Prior to abuse, only two of the victims in this study would have told their parent if they were worried about something online, this increased to five after the abuse (the remaining three would tell a friend). However, this should be considered in light of the fact that the majority of victims were not worried about their relationship with the offender during online contact and thus, using this definition, would not have told their parents about it. However, having had little or no Internet safety education at this point, the victims may have been unaware of the dangers of the situation. This could potentially be changed by better education about online safety.

It is unrealistic and too simplistic to only make recommendations about parental monitoring in response to this growing phenomenon. Teenagers and pre-adolescents outside of the home (e.g., in the playground, at friends' houses) are less under the watchful eye and control of parents and require an empowering and holistic response from education, parents/carers and wider society. Clearly articulated by the victims during interviews was the recommendation that Internet safety be discussed and started from a young age, both at school and at home.

\section{Limitations\& Implications for Future Research}

There are several limitations of this study which require consideration when interpreting the results. The length of time between the discovery of abuse and the research interview varied considerably and in some cases were several years. This is likely to have impacted the way the victims interpreted what happened and details may have been omitted, particularly when the events occurred some time ago. It is suggested that future research includes victims with a shorter period between abuse and interview, to prevent the influence of cognitive maturity and increase the likelihood of clear memories.

The sample for this study is small and therefore the application of these results to wider populations is tentative. In particular, the findings relating to the third victim vulnerability scenario (online behavioral risks) and subsequent minimal apparent issues following abuse, is based on just one individual. This relationship requires further exploration in future research. Similarly, the two males within this study gave less information than the females during interview and it is important to consider factors that might have affected this, such as the fact that the interviewer was female.

Future quantitative research on participants with the same characteristics, (e.g. living in the same location), would be beneficial to explore the impact of online grooming and sexual abuse on issues such as understanding abuse; coping with abuse and the support received.

\section{Conclusion}

This study is the first to highlight links between the way young people become vulnerable to online grooming and the impact the abuse subsequently has on them. The development of victim vulnerabilities and typologies, and how these affect victim impact offer new contributions to this area. Not least because if more evidence is found for the online behavioural risk group, it suggests we must move beyond current ideas about which young people are vulnerable and which are not. This research has shown that young people not particularly at risk offline can be at risk online. In particular, this is an important message for parents and young people. However, additional research is needed to further investigate this relationship.

Victims voices have told us that the experiences they have with professionals are fundamental in contributing to lessening the negative impact of online grooming and sexual abuse. Thus, incorporating the experiences of victims of abuse into our knowledge base can add value to existing work in this area and inform best practice. For example, this study could contribute to the continued development of police roles with victims of child abuse investigations, as well as ABE interviewing, counselling services and the education community.

Online abuse is also still a relatively unknown/unspoken phenomenon amongst young people. Given the rapid rise in the rates of such crimes, a coherent understanding and evidence-based response needs to be formulated in order to: 1) prevent grooming and sexual abuse and, 2) mitigate the effects after such abuse has occurred. This could be assisted by consistent awareness campaigns, further supported by community and societal responses. Hence, there is an urgent need for a coherent societal response to this issue, acknowledging that whilst parents are vital in preventative approaches, they are not the only gatekeepers.

\section{Acknowledgements}

The first author of this paper is funded by the Child Exploitation and Online Protection (CEOP) centre and the University of Birmingham as part of a collaborative studentship. CEOP have approved submission of this paper.

Thank you to Dr. Elly Farmer and DC Tom Simmons for 
reading early drafts of this paper. Thank you also to Dr. Joe Sullivan for contributions during the early stages of analysis.

There are no conflicts of interest with other people or organizations that could inappropriately influence, or be perceived to influence this work.

This work has not been published previously, is not under consideration for publication elsewhere, and is approved by all authors.

\section{REFERENCES}

[1] Whittle, H., Hamilton-Giachritsis, C., Beech, A., \&Collings, G. (2013a). A review of online grooming: characteristics and concerns. Aggression and Violent Behavior, 18, 62-70. DOI:10.106/j.avb.2012.09.003.

[2] Kloess, J. A., Beech, A. R., Harkins, L. (In Press). Online child sexual exploitation: Prevalence, process, offender characteristics. Trauma, Violence \& Abuse.

[3] Mitchell, K. J., Jones, L. M., Finkelhor, D., \&Wolak, J. (2011). Internet-facilitated commercial sexual exploitation of children: Findings from a nationally representative sample of law enforcement agencies in the United States. Sexual Abuse: A Journal of Research and Treatment 23, 43-71. DOI: $10.1177 / 1079063210374347$.

[4] Craven, S., Brown S., \& Gilchrist, E. (2006). Sexual grooming of children: Review of literature and theoretical considerations. Journal of Sexual Aggression, 12,287-299. DOI: $10.1080 / 13552600601069414$.

[5] Whittle, H., Hamilton-Giachritsis, C., Beech, A., \&Collings, G. (2013b). A review of young people's vulnerabilities towards online grooming. Aggression and Violent Behavior, 18, 135-146. DOI:10.1016/j.avb.2012.11.008.

[6] Department for Children, School and Families (2010). Working together to safeguard children: A guide to inter-agency working to safeguard and promote the welfare of children. London, DCSF. Available at http://webarchive.nationalarchives.gov.uk/20130401151715/ https://www.education.gov.uk/publications/eOrderingDownl oad/00305-2010DOM-EN.pdf

[7] Farmer, E. (2010). NSPCC Inform Briefing: What do we know about child sexual abuse? A Review of the Literature. Unpublished Manuscript.

[8] Hillberg, T., Hamilton-Giachritsis, C., Dixon, L. (2011). Review of meta-analyses on the association between child sexual abuse and adult mental health difficulties: A systematic approach. Trauma, Violence, \& Abuse, 12, 38-49. DOI: $10.1177 / 1524838010386812$.

[9] Colman, R. A., \&Widom, C. S. (2004). Childhood abuse and neglect and adult intimate relationships: A prospective study. Child Abuse and Neglect, 28, 1133-1151.

[10] Roberts, R., O’Connor, T., Dunn, J., \& Golding, J. (2004). The effects of child sexual abuse in later family life; mental health, parenting and adjustment of offspring. Child Abuse and Neglect, 28, 525-545. DOI:

10.1016/j.chiabu.2003.07.006.
[11] Andrews, B. A., Brewin, C. R., Rose, S., \& Kirk, M. (2000). Predicting PTSD symptoms in victims of violent crime: The role of shame, anger and childhood abuse. Journal of Abnormal Psychology, 109, 69-73.

[12] Spataro, J., Mullen, P. E., Burgess, P. M., Wells, D. L., Moss, S. A. (2004). Impact of child sexual abuse on mental health: Prospective study in males and females. British Journal of Psychiatry, 184, 416-421.

[13] Dube, S. R., Anda, R. F., Whitfield, C. L., Brown, D. W., Velitti, V. J., Dong, M., Giles, W. H. (2005). Long-term consequences of childhood sexual abuse by gender of victim. American Journal of Preventative Medicine, 28, 430-438. DOI: 10.1016/j.amepre.2005.01.015.

[14] Fergusson, D. M., Boden, J. M., \&Horwood, L. J. (2008). Exposure to childhood sexual and physical abuse and adjustment in early adulthood. Child Abuse and Neglect, 32, 607-619. DOI:10.1016/j.chiabu.2006.12.018.

[15] Bebbington, P. D., Cooper, C., Minot, S., Brugha, T. S., Jenkins, R., Meltzer, H., \& Dennis, M. (2009). Suicide attempts, gender and sexual abuse: Data from the 2000 British Psychiatric Morbidity Survey. American Journal of Psychiatry, 166, 1135-1140. DOI: 10.1176/appi.ajp.2009.09 030310.

[16] Yates, T. M., Carlson, E. A., Egeland, B. (2008). A prospective study of child maltreatment and self-injurious behavior in a community cample. Development and Psychopathology, 20, 651-671.DOI: 10.1017/S09545794080 00321

[17] Marriott, C., Hamilton-Giachritsis, C., Harrop, C. (in press). Factors promoting resilience following childhood sexual abuse: A structured, narrative review of the literature. Child Abuse Review. DOI: 10.1002/car.2258

[18] Fortier, M. A., DiLillo, D., Messman,-Moore, T. L., Peugh, J., DeNardi, K. A., \&Gaffey, K. J. (2009). Severity of child sexual abuse and revictimization: The mediating role of coping and trauma symptoms. Psychology of Women Quarterly, 33, 308-320.

[19] Barnes, J. E., Noll, J. G., Putnam, F. W., \&Trickett, P. K. (2009). Sexual and physical revictimization among victims of severe childhood sexual abuse. Child Abuse and Neglect, $33,412-420$.

[20] Finkelhor, D., Ormrod, R., Turner, H. A., \& Holt.. (2009). Pathways to poly-victimization. Child Maltreatment, 14, 316-329. DOI: $10.1177 / 1077559509347012$.

[21] Hamilton, C. E., \& Browne, K. D. (1999). Recurrent maltreatment during childhood: A survey of referrals to police child protection units in England. Child Maltreatment, 4, 275-286. DOI: 10.1177/1077559599004004001.

[22] Saunders, B. E., (2003). Understanding children exposed to violence: Toward an integration of overlapping fields. Journal of Interpersonal Violence, 18, 356-376. DOI: $10.1177 / 0886260502250840$.

[23] Finkelhor, D., Ormrod, R., \& Turner, H. A. (2007). Poly-victimization: A neglected component in child victimization. Child Abuse \& Neglect, 31, 7-26. DOI: 10.1016/j.chiabu.2006.06.008.

[24] Leonard, M. M. (2010). "I did what I was directed to do but he didn't touch me": The impact of being a victim of internet 
offending. Journal of Sexual Aggression, 16, 249-256.DOI: $10.1080 / 13552601003690526$.

[25] Wolak, J., Mitchell, K. J., \&Finkelhor, D. (2006). Online victimization of youth: Five years later.National Center for Missing \&Exploitated Children. USA.

[26] Mitchell, K. J., Ybarra, M., \&Finkelhor, D., (2007). The relative importance of online victimization in understanding depression, delinquency, and substance use. Child Maltreatment, 12, 314-324. DOI: 10.1177/10775595017305 996.

[27] Mitchell, K. J., Finkelhor, D., Wolak, J., Ybarra, M., \& Turner, H. (2011). Youth internet victimization in a broader victimization context. Journal of Adolescent Health, 48, 128-134. DOI: 10.1016/j.adohealth.2010.06.009.

[28] Ortega, R., Elipe, P., Mora-Merchán, J. A., Genta, M. L., Brighi, A., Guarini, A., Smith, P. K., Thompson, F., \&Tippett, N. (2012). The emotional impact of bullying and cyberbullying on victims: A European cross-national study. Aggressive Behavior, 38.342-356. DOI: 10.1002/ab.21440.
[29] Holloway, I. \&Todres, L. (2003). The status of method: flexibility, consistency and coherence, In Braun, V. and Clarke, V. (2006). Using thematic analysis in psychology. Qualitative Research in Psychology, 3,77 - 101

[30] Braun, V. \& Clarke, V. (2006). Using thematic analysis in psychology. Qualitative Research in Psychology, 3, 77-101. DOI:10.1191/1478088706qp063oa.

[31] Ministry of Justice. (2011). Achieving best evidence in criminal proceedings: Guidance on interviewing victims and witnesses, and guidance on using special measures. Crown Copyright

[32] Bronfenbrenner, U. (1979). The ecology of human development: experiments by nature and design. Cambridge, MA: Havard University Press.

[33] Hamilton, C.E., Falshaw, L.,\& Browne, K.D. (2002). The links between recurrent maltreatment and offending behaviour. International Journal of Offender Therapy and Comparative Criminology, 46(1), 75-94 